\title{
O PAPEL DA AUDITORIA EXTERNA PARA MELHORIA DOS PROCESSOS DE CONTROLE DE ESTOQUES NAS EMPRESAS DE MÉDIO PORTE NO RAMO INDUSTRIAL
}

\section{ARTIGO ORIGINAL}

PANTOJA, Rayanne dos Santos ${ }^{1}$, SOUSA, JUNIOR, Olavo Carneiro de ${ }^{2}$, QUEIROZ, Caio Cavalcante Alves de ${ }^{3}$, BAIMA, Janneson Lima ${ }^{4}$, ROBERTO, José Carlos Alves $^{5}$, SERRA, Meg Rocha da Cunha ${ }^{6}$, LOPES, Nelânia Ferreira ${ }^{7}$

PANTOJA Rayanne Dos Santos. Et al. O papel da auditoria externa para melhoria dos processos de controle de estoques nas empresas de médio porte no ramo industrial. Revista Científica Multidisciplinar Núcleo do Conhecimento. Ano 06, Ed. 11, Vol. 02, pp. 178-203. Novembro de 2021. ISSN: 2448-0959, Link de acesso: https://www.nucleodoconhecimento.com.br/contabilidade/processos-de-controle, DOI: 10.32749/nucleodoconhecimento.com.br/contabilidade/processos-de-controle

\section{RESUMO}

O presente estudo bibliográfico busca discutir aspectos relativos à auditoria externa que trabalha com métodos de avaliação de desempenho em comparação com o almejado, o que conduz ao surgimento de diferentes orientações a fim de aprimorar o desenvolvimento, alcançando o sucesso da empresa. Em virtude de os estoques das empresas industriais possuírem um alto índice de rotatividade é necessário que o controle desses materiais tenha procedimentos que atendam os critérios

\footnotetext{
${ }^{1}$ Graduanda do curso de contabilidade.

${ }^{2}$ Graduando do curso de Contabilidade.

${ }^{3}$ Graduando do curso de contabilidade.

${ }^{4}$ Graduando do curso de contabilidade.

${ }^{5}$ Orientador. Mestre em Engenharia de produção. Especialista Logística empresarial. Graduado em Administração com Ênfase em Marketing.

${ }^{6}$ Orientadora. Mestra em Engenharia de Processos Industriais pela UFPA, especialista em Controladoria e Auditoria Contábil pelo Ciesa (2020), Graduada em Ciências Contábeis pelo Centro Universitário do Norte (2010). Graduada em Ciências Econômicas pelo Centro Universitário do Norte (2006).

${ }^{7}$ Orientadora. Especialista em Auditoria Contábil, Financeira e Tributária e Graduada em Ciências Contábeis.
}

RC: 100655

Disponível em: https://www.nucleodoconhecimento.com.br/contabilidade/processosde-controle 
gerenciais e fiscais. Neste contexto, o presente artigo, tem como questão norteadora: Como a auditoria externa pode contribuir nos processos de controle de estoques em empresas de médio porte do ramo industrial? Este estudo teve como objetivo geral descrever o papel de trabalho da auditoria externa nos procedimentos de controle de estoques nas indústrias de médio porte. Esta temática é caracterizada como uma pesquisa bibliográfica, realizada em livros, artigos científicos e dissertações que se encontravam disponíveis em bibliotecas virtuais. $A$ partir da realização da auditoria externa ocorre a contribuição para a realização dos registros contábeis. Conclui-se que o principal objetivo da auditoria externa é verificar a integridade e a exatidão das informações e documentos contábeis demonstrados por uma organização, possibilitando desenvolver métodos preventivos para melhorias de resultados, principalmente nos processos de controle de estoques.

Palavras-chave: Auditoria externa, controle de estoques, registros contábeis.

\section{INTRODUÇÃO}

A partir da contabilidade, começou os procedimentos de auditoria, dando início estudo, ao levantamento, avaliações financeiras de uma empresa (TOSCAN, 2019). Segundo Lins (2017), é possível afirmar que além de assumir caráter esclarecedor, o procedimento de auditoria é responsável pela comunicação dos resultados dentro de um determinado objetivo, estabelecido e proposto pelo planejamento da auditoria.

A auditoria externa envolve o setor de estoque, formado por bens voltados a fabricação e a venda, visando alcançar lucros para a organização. Seus principais objetivos são, especificar a existência do estoque que pode estar sendo dominada por terceiros, analisar se estão sendo aplicados de forma adequada os princípios da contabilidade, se as notas explicativas estão sendo divulgadas corretamente e se suas demonstrações estão classificadas de forma adequada. 
As empresas buscam constantemente melhorias na entidade, deste modo, o estoque é um setor que demanda a todo o momento, melhorias, posto que, é a partir do adequado armazenamento e lançamento dos componentes no sistema da indústria ocorrerá a existência física. Sendo assim, ocorrerá a partir de um eficiente controle interno, redução de falhas no processo, na organização do estoque e de registros contábeis da empresa, antes da realização da auditoria externa, ocorriam constantes prejuízos de materiais, atrasos de fornecimento de peças para o setor produtivo, como consequência redução de produção e atraso na entrega de produtos.

O monitoramento de movimentação é um bom controle de estoque, são atividades necessárias para o alcance da competividade e lucratividade das indústrias, mas, os custos do controle de estoque não devem ultrapassar os benefícios que ele permite. Desta maneira, surge a seguinte pergunta, problema: Como a auditoria externa pode contribuir nos processos de controle de estoques empresas de médio porte do ramo industrial?

Este estudo é relevante por apresentar o processo da auditoria externa enquanto instrumento de administração no auxílio nas atribuições do setor de estoque. Logo, a auditoria possui a finalidade de avaliar todas as especialidades da qualidade dos serviços oferecidos pelos contadores, assim, como sua conduta diante do mercado e empresa.

Deste modo, este estudo tem como objetivo geral descrever o papel de trabalho da auditoria externa nos procedimentos de controle de estoques nas indústrias de médio porte. E como objetivos específicos, apresentar a definição de auditoria, identificar as características das empresas de médio porte e demonstrar os procedimentos práticos pela auditoria externa.

RC: 100655

Disponível em: https://www.nucleodoconhecimento.com.br/contabilidade/processosde-controle 


\section{FUNDAMENTAÇÃO TEÓRICA}

A fundamentação teórica baseia-se na análise de artigos, livros, textos, todos os assuntos relacionados a revisão de literatura sendo utilizada na elaboração da temática. É o período de realizar a leitura, apurar, elucidar e debater o material do trabalho. Ela visa embasar através de teorias de vários autores componentes teóricos de seu estudo, servindo de fundamento para analisar e interpretar informações coletados no decorrer de construção do trabalho de conclusão de curso (PORTAL EDUCAÇÃO, 2021).

\subsection{DEFINIÇÃO DE AUDITORIA}

Para Nascimento (2020), a implantação de um departamento de auditoria deve seguir as formas de valores, conforme sua competência. Assim, a definição de auditoria começa com a avaliação do processo, utilizada em diversas áreas, relacionado aos conceitos de transparência e responsabilidade, pois, a auditoria desenvolve um papel estratégico e de responsabilidade social, quando tem a possibilidade de promover a transparência da informação no momento certo, agindo a partir das demonstrações financeiras.

Segundo o CRC-CE (2016), a auditoria tem como finalidade analisar a exatidão dos registros contábeis, como um dos seus objetivos, se atentando para as demonstrações contábeis, isso faz parte dos procedimentos que alteram o patrimônio de uma empresa. A auditora se apresenta como uma técnica bastante utilizada para investigar dados contábeis de um empreendimento, visando expressar opinião acerca do controle patrimonial e das demonstrações contábeis, transparecendo a realidade da empresa (TRINDADE; PEREIRA; THEREZA, 2017).

\subsubsection{OBJETIVOS DA AUDITORIA EXTERNA}

A auditoria externa é definida como uma metodologia que visa desenvolver e atuar transmitindo segurança e confiabilidade, em relação às informações transmitidas 
pela companhia. Isto é, será somente através da auditoria externa que os acionistas e potenciais investidores, terão compreensão de que a empresa é transparente e que seus números são verdadeiros (REIS, 2018).

A auditoria tem como objetivo, o domínio do conjunto de métodos do patrimônio administrativo, pelos quais, possuem papéis, documentos, fichas, registros contábeis, arquivos e anotações para comprovar a veracidade dos fatos (CREPALDI, 2016). Logo, o objetivo atua na defesa da integridade da empresa e quando o programa de auditoria externa trabalha pensando em alcançar seus propósitos, o nível de competência desenvolve na indústria. Sendo assim, começa a melhorar a imagem da empresa junto ao mercado, facilitando a conquista de novos investimentos e aportes (CARVALHO; PEREIRA, 2016).

\subsection{CONCEITO DE ESTOQUE}

Segundo Gonçalves (2017), o estoque é qualquer quantidade de materiais e/ou bens que ficam alocados na organização, em que estão temporariamente improdutivos, porém, com previsão de serem utilizados no futuro. Pode-se considerar que seria o conjunto de itens tangíveis que a empresa tem alocado, tendo como objetivo atender as necessidades do mercado.

Para Silva e Loos (2016), os estoques são ativos que permitem economias na produção, assim como, normalizam as diferenças de ritmos entre os fluxos importantes de uma companhia. Ocorrendo organização nos produtos do estoque (GASNIER et al., 2018).

\subsection{DEFINIÇÃO DE EMPRESAS INDUSTRIAIS}

Atualmente, as indústrias estão cada vez mais buscando modernização, e essa transformação conquista espaço no chão das fábricas, com o desenvolvimento tecnológico. Assim, as empresas podem criar redes inteligentes no percurso do seu 
processo produtivo, e essa integração contribui com uma aplicação da produção com qualidade nos serviços (SOUZA, 2018).

Segundo Martins (2018), as empresas se encontram em um mercado que possui constantes transformações, o que demanda informações e controle de seu negócio, para adequar suas operações às novas condições do mercado. As empresas industriais precisam se preparar para enfrentar um período favorável em várias condições, para grande das empresas, a receita perdida nesse tempo, pode resultar em uma perda permanente, exigindo de forma inesperada sua liquidez e seus orçamentos econômicos (MACHADO, 2020).

\subsubsection{PROCESSO DE ESTOQUES NA INDÚSTRIA}

Segundo Nunes et al. (2020), para reduzir custos nas empresas, existem procedimentos a serem aplicados, um deles, está relacionado ao processo do estoque. Quando é trabalhado todo método de forma correta, pode controlar as quantidades de produtos disponíveis nas áreas específicas na indústria.

Nas indústrias, são desenvolvidos todos os métodos de estoque, que sejam aproveitados para promover serviços de qualidade, os níveis adequados, devem garantir uma análise, programa e controle que possibilite que as organizações sobrevivam ao longo dos anos. Para isso, todo esforço é importante na distribuição de materiais, principalmente para atender as necessidades apresentadas (DANTAS, 2020).

\subsubsection{CONTROLE DE INSUMOS}

Os insumos são classificados como fatores de produção como, horas de trabalho, máquinas, capital, dentre outros. Caso o insumo, tenha uma procura elevada e a oferta não for acessível, o seu valor tende a crescer, a produção, com mudanças de insumos, em produtos ou serviços para a venda, acaba interferindo no orçamento (AVILA, 2020).

RC: 100655

Disponível em: https://www.nucleodoconhecimento.com.br/contabilidade/processosde-controle 
Sendo assim, a matéria-prima pode ser um insumo, porém, é mais utilizado do que uma matéria prima. A matéria-prima é o material fundamental de um produto, deste modo, a produtividade torna-se uma relação entre o nível do produto e a quantidade do fator de produção, por isso, que os materiais seguem um tempo estimado, representando a colaboração média de cada fator de produção (VARIAN, 2015).

\subsubsection{CONTROLE DE PROCESSO EM ELABORAÇÃO}

Os determinados produtos em processos, denominados, produtos de elaboração, possui, papel importante na fase de acabamento industrial. $O$ produto de elaboração, não pode ficar separado, nem identificado como independentes dos produtos acabados, as chamadas matérias-primas. Portanto, os produtos em desenvolvimento se encontram de forma parcial, acabados, estão no estágio intermediário do processo produtivo (BARBOSA, 2017).

Produtos em elaboração devem ter o controle não custo de falta, sempre devem passar pela manutenção para compreenderem se a quantidade é suficiente para atender ao processo, evitando interrupção dele. Todo esse cuidado, é para prevenir custos por vendas perdidas, atrasos na entrega e ociosidade, contudo, o estoque de elaboração de materiais deve ser realizado sempre pensando nos impactos que podem ocorrer no processo, sem gerar custos agressivos (PYKE; SILVER; THOMAS, 2017).

\subsubsection{CONTROLE DE PRODUTO ACABADO}

Segundo Mendonça (2019), os produtos já fabricados e completos e estão armazenados, devem ser despachados, quando vendidos, para não gerar acúmulo de materiais. Organizações que têm suas atividades de vendas através de pedidos não estocam grandes quantidades de estoque, logo, após a saída dos produtos acabados automaticamente a empresa partilha suas encomendas. 
O produto acabado é voltado ao consumidor final, este leva, o produto caso tenha alguma mudança para comercialização retorne para mais uma revisão. O estoque de produtos acabados caracteriza-se pelos produtos que já estão prontos para vendas, vindo do processo produtivo da empresa ou comprados de outros fornecedores, contudo, que nesses produtos são encontradas grandes capacidades de investimentos para comercialização (SILVA, 2019).

\subsection{EMPRESAS INDUSTRIAIS DE MÉDIO PORTE}

O termo empresa, pode ser entendido como um processo e como produto desse mesmo processo, estas estabelecem atribuições e relações entre os recursos e órgãos da empresa. Define essas tarefas, de maneira, a atuar frente a divisão do trabalho, através da hierarquia, autoridade e responsabilidade, sendo que, o resultado do processo de organizar, é o desenvolvimento de uma organização em duas ou mais pessoas que desenvolvem seu trabalho em conjunto (MACHADO et al., 2015).

Desenvolver sobre as características das empresas de médio porte, é discutir sua formação e preparo, pois deve ter uma adaptação adequada de conhecimento acerca dessas características. No quadro 1, são apresentadas as classificações das empresas, de acordo o número de empregados, no quadro 2, relacionado ao setor.

Quadro 1 - Classificação das Empresas Segundo o Número de Empregados.

\begin{tabular}{|l|l|l|}
\hline Porte da Empresa & Comércio e Serviços & Indústria \\
\hline Microempresa & Até 9 & Até 19 \\
\hline $\begin{array}{l}\text { Empresa de Pequeno } \\
\text { porte }\end{array}$ & 10 a 49 & 20 a 99 \\
\hline Empresa de Médio porte & 50 a 99 & 100 a 499 \\
\hline Empresa de Grande porte & $>99$ & $>499$ \\
\hline
\end{tabular}

Fonte: Sebrae (2014).

RC: 100655

Disponível em: https://www.nucleodoconhecimento.com.br/contabilidade/processosde-controle 
No quadro 1 pode-se observar o porte da empresa é determinado devido a quantidade de trabalhadores atuantes e dependentes da área do setor econômico, pesquisado. As microempresas da área do comércio e serviços, possuem até 9 funcionários, do setor da indústria até 19 colaboradores, as empresas de pequeno porte do setor do comércio e serviços, possuem o proporcional de 10 a 49 funcionários, da indústria de 20 a 99 trabalhadores, as empresas de médio porte, setor do comércio e serviços, 50 a 99, indústria, 100 a 499 e por fim, as empresas de grande porte do comércio e serviços, 99 e da indústria 499.

\subsubsection{MÉTODOS DE CONTROLE DE ESTOQUES DA INDÚSTRIA}

O controle de estoque é de grande relevância para as indústrias. Para realizar o controle de estoque, é fundamental conduzir o produto ou material, começando de sua vida no setor de estoque (recebimento), (estocagem) ao ser entregue ao cliente final (RUSSO, 2013). Deste modo, o estoque pode ser classificado como produtos, matérias-primas, produtos acabados e produtos semiacabados que as indústrias usam e que se encontram acondicionados nas suas dependências, porém, é necessário um controle e planejamento nas ações logísticas para ser desenvolvido com eficácia.

Essa técnica é utilizada por diversas organizações com a finalidade de desenvolver a gestão do processo de produção, visando elevar a capacidade, trazendo proveitos para a indústria (AMORIM, 2016). Após demonstrar a necessidade dos estoques para o alcance dos resultados das empresas, cabe evidenciar ser de grande relevância a apropriada análise desse tipo de estoque, deste modo, afetará os custos na produção. A partir disso, serão destacados os principais métodos de análise dos estoques como: UEPS, PEPS, Custo Médio e/ou Média Ponderada (SANTOS; BORGES, 2020). 


\subsubsection{PEPS}

Silva (2019) explícita que o PEPS, também conhecido de FIFO (first in first out) é a metodologia mais utilizada nas indústrias, pois, é incumbida por reduzir custos e perdas indevidas com estoques velhos. O método PEPS determina que o primeiro componente alojado no estoque, deve ser baixado por condições de vendas, com seu concernente valor de inclusão.

Os benefícios do PEPS ocorrem em valores aproximados ao do mercado atual, as despesas de mercadorias comercializadas podem apresentar alteração e uma redução do valor, pois, emprega como cálculo as partes no começo. O estoque PEPS se baseia no primeiro que entra, e o primeiro que sai do local (SILVA et al., 2018).

Quadro 2- Modelo prático do PEPS

\begin{tabular}{|c|c|c|c|c|c|c|c|c|c|}
\hline \multicolumn{3}{|c|}{ ENTRADA } & \multicolumn{3}{|c|}{ SAÍDA } & \multicolumn{4}{|c|}{ SALDO } \\
\hline $\begin{array}{l}\text { Históri } \\
\text { co }\end{array}$ & $\begin{array}{l}\text { Quan } \\
\text { t. }\end{array}$ & $\begin{array}{l}\text { Unida } \\
\text { de }\end{array}$ & Total & $\begin{array}{l}\text { Quan } \\
\text { t. }\end{array}$ & Unid & Total & $\begin{array}{l}\text { Quan } \\
\text { t. }\end{array}$ & $\begin{array}{l}\text { Unida } \\
\text { de }\end{array}$ & Total \\
\hline $\begin{array}{l}\text { Compr } \\
\text { as }\end{array}$ & 100 & 20,00 & $\begin{array}{l}2.000 \\
00\end{array}$ & ----- & ----- & & 100 & 20,00 & $\begin{array}{l}2.000 \\
00\end{array}$ \\
\hline $\begin{array}{l}\text { Compr } \\
\text { as }\end{array}$ & 120 & 22,00 & $\begin{array}{l}2.640, \\
00\end{array}$ & ----- & ----- & & $\begin{array}{l}120 \\
220\end{array}$ & 22,00 & $\begin{array}{l}2.640, \\
00 \\
4.640 \\
00\end{array}$ \\
\hline & ----- & ----- & & 80 & $\begin{array}{l}20,0 \\
0\end{array}$ & $\begin{array}{l}1.600 \\
00\end{array}$ & 20 & 20,00 & 400,00 \\
\hline Venda & & & & & & & $\begin{array}{l}120 \\
140\end{array}$ & 22,00 & $\begin{array}{l}2.640 \\
00\end{array}$ \\
\hline Venda & & & & 20 & $\begin{array}{l}20,0 \\
0\end{array}$ & $\begin{array}{l}400,0 \\
0\end{array}$ & & & $\begin{array}{l}3.040, \\
00\end{array}$ \\
\hline
\end{tabular}

RC: 100655

Disponível em: https://www.nucleodoconhecimento.com.br/contabilidade/processosde-controle 


\begin{tabular}{|l|l|l|l|l|l|l|l|}
\hline Venda & 20 & 22,0 & 440,00 & 100 & & 2.200 \\
& & & 0 & & & 22,00 & 00 \\
\hline & 40 & & 840,00 & & & \\
\hline
\end{tabular}

Fonte: Carvalho (2021).

No Quadro 2 pode-se observar que primeiramente foi realizada a compra de 100 unidades, a prazo a $R \$ 20,00$, dando um total de $R \$ 2.000,00,122$ unidades $R \$$ 22,00 sendo a vista, total de $R \$ 2.640,00$, 80 unidades ao cliente ao preço de $R \$$ 40,00 unidade à vista, 40 unidades ao cliente ao valor de $R \$ 60,00$ a unidade a prazo, totalizando $\mathrm{R} \$ 840,00$.

\subsubsection{UEPS}

No modelo controle de estoque PEPS, ainda conhecido como First In First Out FIFO, é o recurso em que as primeiras mercadorias que entram, assim, na forma que percorrer as saídas, ocorre a diminuição dos estoques a partir das primeiras compras (DA SILVA; OLIVEIRA, 2019).

É importante compreender que a UEPS, é um procedimento de controle de estoque com finalidade de permitir ao gestor definir de diversas maneiras, qual será o custo das mercadorias vendidas, isto é, por qual preço os materiais foram comprados quando deram entrada no estoque (BETENCOURT, 2018).

Esse procedimento fundamenta-se na finalidade que os últimos produtos a adentrarem no estoque, sejam os primeiros a serem retirados, dando, prioridade aos estoques mais recentes (SILVA et al., 2018). Santos e Borges (2016) descrevem que na UEPS, é utilizado o último preço de obtenção para objetivos de baixo estoque. Esse método de avaliação atinge o custo de restituição e atende os princípios do conservadorismo, porém, é percebido como oposto a lei da legislação brasileira. 
Quadro 3- Modelo prático do UEPS

\begin{tabular}{|c|c|c|c|c|c|c|c|c|c|}
\hline \multicolumn{3}{|c|}{ ENTRADA } & \multicolumn{3}{|l|}{ SAÍDA } & \multicolumn{4}{|c|}{ SALDO } \\
\hline $\begin{array}{l}\text { Históri } \\
\text { co }\end{array}$ & $\begin{array}{l}\text { Quan } \\
\text { t. }\end{array}$ & $\begin{array}{l}\text { Unida } \\
\text { de }\end{array}$ & Total & $\begin{array}{l}\text { Quan } \\
\text { t. }\end{array}$ & Unid & Total & $\begin{array}{l}\text { Quan } \\
\text { t. }\end{array}$ & $\begin{array}{l}\text { Unida } \\
\text { de }\end{array}$ & Total \\
\hline $\begin{array}{l}\text { Compr } \\
\text { as }\end{array}$ & 100 & 20,00 & $\begin{array}{l}2.000 \\
00\end{array}$ & ----- & ----- & & 100 & 20,00 & $\begin{array}{l}2.000 \\
00\end{array}$ \\
\hline $\begin{array}{l}\text { Compr } \\
\text { as }\end{array}$ & 120 & 22,00 & $\begin{array}{l}2.640, \\
00\end{array}$ & ----- & ----- & & $\begin{array}{l}120 \\
220\end{array}$ & 22,00 & $\begin{array}{l}2.640, \\
00 \\
4.640 \\
00\end{array}$ \\
\hline Venda & ----- & ----- & & 80 & $\begin{array}{l}22,0 \\
0\end{array}$ & $\begin{array}{l}1.760, \\
00\end{array}$ & 100 & 20,00 & $\begin{array}{l}2.000 \\
00\end{array}$ \\
\hline Venda & & & & & & & $\begin{array}{l}40 \\
140\end{array}$ & 22,00 & $\begin{array}{l}880,00 \\
2.880, \\
00\end{array}$ \\
\hline Venda & & & & 40 & $\begin{array}{l}22,0 \\
0\end{array}$ & $\begin{array}{l}880,0 \\
0\end{array}$ & 100 & 20,00 & $\begin{array}{l}2.000 \\
00\end{array}$ \\
\hline \multicolumn{10}{|l|}{ Venda } \\
\hline & & & $\begin{array}{l}4.640, \\
00\end{array}$ & & & $\begin{array}{l}2.640, \\
00\end{array}$ & & & $\begin{array}{l}2.000 \\
00\end{array}$ \\
\hline
\end{tabular}

Fonte: Carvalho (2021).

No Quadro 3 pode-se observar que primeiramente foi realizada a compra de 100 unidades, a prazo a $R \$ 20,00$, dando um total de $R \$ 2.000,00,122$ unidades a $R \$$ 22,00 , total de $R \$ 2.640,00$, somando $R \$ 4.640,00,80$ unidades ao cliente ao preço de $\mathrm{R} \$ 22,00$ unidade à vista, total de $\mathrm{R} \$ 1.760,00$, de 100 unidades, dando baixa em 40 , restaram 60. Deste modo, o total das entradas ficaram em $\mathrm{R} \$ 4.640,00$, saída $R \$ 2.640,00$ e o saldo do estoque $R \$ 2.000,00$.

RC: 100655

Disponível em: https://www.nucleodoconhecimento.com.br/contabilidade/processosde-controle 


\subsubsection{CUSTO MÉDIO}

O custo médio é o critério mais utilizado na sociedade brasileira para a análise de estoques e, em sequência para apuração do custo dos materiais usados nos custos médios considerados móveis, conforme a realidade do desenvolvimento econômico (SILVA, 2018). A empresa sempre tem essa atribuição de controlar seus negócios, logo, o custo médio, é aquele que o empreendimento contém como controle constante de seu estoque e por isso, sempre está atualizando seu preço médio depois de cada aquisição (MACEDO, 2017).

O custo médio ponderado fixo é utilizado quando a empresa calcula o preço médio, somente após finalizar o tempo ou quando busca oferecer todos os produtos elaborados na produção diária ou mensal, num único preço por unidade. Por isso, construir valor de venda é fundamental, é necessário conhecer com detalhes todos os custos operacionais da empresa, estar esperto das transformações do mercado e buscar sempre suprir com eficiência as necessidades do consumidor (CREPALDI; CREPALDI, 2017).

Quadro 4- Modelo prático de Custo Médio

\begin{tabular}{|c|c|c|c|c|c|c|c|c|c|}
\hline Operaç & \multicolumn{2}{|c|}{ ENTRADA } & \multicolumn{3}{|l|}{ SAÍDA } & \multicolumn{4}{|c|}{ SALDO } \\
\hline $\begin{array}{l}\text { Históric } \\
\text { o }\end{array}$ & $\begin{array}{l}\text { Quan } \\
\text { t. }\end{array}$ & $\begin{array}{l}\mathrm{R} \$ \\
\text { Unid. }\end{array}$ & Total & $\begin{array}{l}\text { Quan } \\
\text { t. }\end{array}$ & $\begin{array}{l}\mathrm{R} \$ \% \\
\text { Unid. }\end{array}$ & Total & $\begin{array}{l}\text { Quan } \\
\text { t. }\end{array}$ & $\begin{array}{l}\mathrm{R} \$ \\
\text { Unida } \\
\text { de }\end{array}$ & Total \\
\hline Compra & 10 & $\begin{array}{l}100,0 \\
0\end{array}$ & $\begin{array}{l}1.000, \\
00\end{array}$ & ----- & ----- & & 10 & 100,00 & $\begin{array}{l}1.000, \\
00\end{array}$ \\
\hline Compra & 20 & $\begin{array}{l}130,0 \\
0\end{array}$ & $\begin{array}{l}2.600, \\
00\end{array}$ & ----- & ----- & & 30 & 120,00 & $\begin{array}{l}3.600, \\
00\end{array}$ \\
\hline Venda & & ----- & & 20 & $\begin{array}{l}120,0 \\
0\end{array}$ & $\begin{array}{l}2.400, \\
00\end{array}$ & 10 & 120,00 & $\begin{array}{l}1.200, \\
00\end{array}$ \\
\hline Compra & 40 & 120,0 & 4.800, & & & & 50 & 120,00 & 6.000 \\
\hline
\end{tabular}

RC: 100655

Disponível em: https://www.nucleodoconhecimento.com.br/contabilidade/processosde-controle 


\begin{tabular}{|l|l|l|l|l|l|l|l|l|l|}
\hline Venda & & 0 & 00 & & & & & & \\
& & & 45 & 120,0 & 5.400, & 5 & 120,00 & 600 \\
& & & & 0 & 00 & & & \\
\hline
\end{tabular}

Fonte: Carvalho (2021).

No Quadro 4- pode-se identificar a movimentação do produto $\mathrm{x}$ no mês $\mathrm{y}$, considerando a compra/entrada de 10 unidades ao custo unitário de $R \$ 100,00$, a compra/ entrada de 20 unidades a $\mathrm{R} \$ 130,00$ cada. Venda/saída de 20 unidades, a compra/ entrada de 40 unidades a $R \$ 120,00$ cada, a venda/saída de 45 unidades.

\subsection{PAPEL E PROCEDIMENTOS DA AUDITORIA EXTERNA DE ESTOQUES}

Segundo Crepaldi (2016), afirma que a observação do estoque é considerada um procedimento aceito pelas normas de Auditoria, ele ajuda os auditores a atingirem determinados objetivos, principalmente no que concerne a propriedade, quantidades, existência real e possibilidade de venda. Esta observação do estoque, quando bem-feita, possibilita ao auditor a certeza de características físicas, qualitativas e quantitativas dos estoques. Assim, para controle interno do estoque, alguns procedimentos devem ser executados.

Conforme Borges et al. (2020), a auditoria é uma técnica importante para apurar a integridade contábil de uma determinada empresa. Por isso, a auditoria externa é aquela desenvolvida por um profissional liberal, auditor independente, não contém vínculo de emprego com a empresa auditada, que pode ser contratado para auditoria eventualmente ou permanente.

Auditoria externa não é desenvolvida para identificar fraudes, erros ou para interferir na administração, tampouco, para disciplinar o processo produtivo ou intervir nas demissões das pessoas ineficientes, ela tem o papel de identificar como anda o 
processo operacional da empresa. Contudo, no decorrer da auditoria, o auditor pode encontrar fraudes ou erros, mas, seu objetivo não é somente este (ALMEIDA, 2018).

A auditoria deve estar presente em qualquer situação do estoque, seja na conferência de mercadorias recém-chegadas ou mercadorias vendidas. Segundo Almeida (2012) um dos procedimentos de auditoria é a verificação da existência física, ele afirma que para uma empresa ter um levantamento de inventário bemsucedido é necessário adotar os seguintes detalhes:

- Planejamento;

- Controle de etiquetas;

- Corte das operações;

- Movimentação externa e interna de produtos;

- Identificação dos produtos.

Almeida (2012) afirma que os principais objetivos da auditoria de estoques são os seguintes:

- Verificar as quantidades de bens declaradas realmente existem;

- Verificar se os bens foram custeados e avaliados de acordo com os princípios fundamentais de contabilidade e a constância dos procedimentos em relação ao exercício social anterior;

- Verificar se as informações referentes aos estoques foram adequadamente divulgadas nas demonstrações financeiras sob exame (classificação, notas explicativas sobre os estoques dados em garantia e mudança na base de avaliação com efeito relevante).

Filho (2008) descrimina os procedimentos de auditoria dos estoques da seguinte forma:

a) O procedimento inicial a ser executado pelo auditor, é o confronto entre o saldo apresentado no Balanço e o saldo declarado no livro registro de inventário. As 
diferenças a maior verificadas na contabilidade podem caracterizar a superavaliação dos estoques, podendo levar o auditor a concluir que ocorreu omissão de receitas.

b) A comprovação física dos estoques também é indispensável. A verificação pode ser realizada através de testes estatísticos, mas, é recomendável que se esteja atento à medida ou extensão.

Quando houver dificuldades para contagem ou medição do material o auditor deve também apelar para o sentido prático, usando de cubagens etc., a fim de facilitar o trabalho e não o tornar demasiadamente lento quanto a verificação. Deve ser procedida a avaliação do controle interno dos estoques, antecedendo a verificação do inventário de modo a ter-se consciência sobre os limites de alcance dos estoques em sua evidenciação e exatidão.

c) O auditor deve proceder obrigatoriamente, ao exame da avaliação dos estoques, pois está correlacionado à comprovação física; analisando os procedimentos da formação dos custos bem como os critérios de avaliação dos estoques. Quando a fixação do valor exigir o conhecimento do preço de mercado ou de reposição, necessário se faz certificar-se das fontes fornecedoras de dados sobre a realidade dos números como também se o critério adotado respeitou o critério do custo ou mercado, dos dois o menor.

d) A veracidade da expressão contábil dos estoques deve ser verificada através do mais amplo exame dos registros, da realidade física, da exatidão aritmética e do valor, em consonância com a legislação fiscal e os princípios fundamentais de contabilidade. O objetivo é que o auditor se certifique de que a cifra constante do Balanço, bem como as apropriações aos custos dos bens de venda que se converteram em receitas, representam de forma adequada a posição e a circulação dos estoques.

e) A abrangência das provas é um critério pessoal do auditor, assim como o método de amostragem, mas, será sempre conveniente que se atribua maior atenção aos bens de maior valor e de maior volume de giro, mas sem tendenciar a amostra.

RC: 100655

Disponível em: https://www.nucleodoconhecimento.com.br/contabilidade/processosde-controle 
f) Quando houver a impossibilidade de verificação dos estoques em armazéns gerais ou consignados a terceiros ou de pouca relevância, bem como aqueles gravados por ônus, o auditor pode recorrer a circularizações de correspondências onde se solicitem dados analíticos sobre as mercadorias, tais como: quantidade, qualidade, especificação completa, codificação, tipo de embalagem, obsoletos, danificados ou incompletos; ou a solicitações de certificados de depósitos ou ônus, solicitando sejam assinados por elementos credenciados dos informantes.

g) O auditor deve atentar para a avaliação dos itens dos estoques que por natureza deve ter seus valores minimizados, como: resíduos, refugos, obsoletos avariados e semelhantes. Se a eles foram atribuídos valores equivalentes ou aproximados dos demais itens do estoque.

h) É recomendável que exista uma correlação entre a auditoria dos estoques, e os custos dos produtos vendidos ou mercadorias vendidas e as vendas, através de integrado critério de exame.

i) Devolução de Vendas - Verificar pelas fichas de estoque, casos de devolução pelos clientes, examinar se as devoluções se processaram com documento fiscal e devidamente lançadas nos livros de entrada de mercadorias; verificar no livro diário e identificar lançamentos contábeis de devoluções.

\subsection{PAPEL DO AUDITOR EXTERNO NA AUDITORIA DOS ESTOQUES}

Segundo Almeida (2018), o auditor externo, além de seu posicionamento ou parecer sobre as demonstrações contábeis, começa a ser fornecido por um relatório comentário, pelo qual, apresentava ideias para solucionar os problemas da empresa, que chegaram a seu conhecimento no curso de sua atividade de auditoria. $\mathrm{O}$ auditor externo permanecia pouco tempo na instituição, e o foco, era a auditoria das demonstrações contábeis. 
O auditor externo deve ainda, apontar se ocorrer prestação justa de contas de um patrimônio e, se os negócios foram acessíveis para serem administrados. Informando aos interessados se existem prejuízos ou lucros, apresentando custos, inventários, também investigando se ocorreram fraudes ou não (DUTRA et al., 2017). O auditor desenvolve seu trabalho como ferramenta de controle e prevenção de ilícitos sobre os dados, se destacando como um componente importante, auxiliando de forma eficiente no alcance das metas e na melhor visão da gestão (FREITAS; SENA, 2019).

\subsubsection{TÉCNICAS E PROCEDIMENTOS DE INVENTÁRIO DE ESTOQUES}

Conforme Coelho (2017), o inventário é escolhido de acordo a necessidade da organização, que pode ser periódico por conta da ausência de sistemas tecnológicos de controle de estoques, pois, esse processo permite erguer e quantificar os custos e saldos. As técnicas do inventário quando desenvolvido no estoque detecta vários problemas permanentes em uma empresa, sendo uma organização de pequeno ou grande porte deve ocorrer esse procedimento.

Segundo Martins e Conceição (2019), o inventário de estoque se característica completa de todos os produtos acomodados no estoque de um empreendimento. Esse inventário pode ser classificado para constatar o valor de cada produto, principalmente na estocagem, recebe com o inventário, auxiliando na redução de custos.

Conforme ludicibus (2017) é essencial compreender que o processo de avaliação correta dos estoques atua de forma direta no Balanço Patrimonial da empresa, por isso, deve seguir conforme as normas, pois, suas conclusões são rápidas em todos os sentidos no Patrimônio Líquido.

Existem atualmente, métodos de avaliação de estoque que pode ser utilizado no Brasil que são: o PEPS ou FIFO, este primeiro entra e primeiro sai, o UEPS, este é o 
último que entra e o primeiro a sai, o Custo médio ponderado, atua no média ponderada móvel - MPM, Custo específico e Método do varejo. Sendo assim, o custo de aquisição dos materiais pode influenciar no valor de venda dos seus produtos, por conta disso, é importante contar com métodos de análise de estoque, isso interfere na lucratividade total (FARIAS; ANJO, 2018).

Segundo Rodrigues et al. (2020), a subavaliação do estoque final tem por finalidade provocar o diferimento da tributação do lucro, dado que, o valor subavaliado no exercício anterior passa a se tornar importante estoque inicial do exercício seguinte. Por isso, ausência do controle essencial respeito ao estoque inviabiliza, e este é o que controla de maneira decisória as finanças da empresa, pois se pode controlar a evitar gastos desnecessários com estocagem, os resultados serão surpreendentes.

Atualmente, as indústrias que utilizam o processo da subavaliação, pode avaliar os estoques por valor inferior ao seu valor real, e isso eleva os custos das mercadorias e produtos vendidos, diminuindo, em seguida, o lucro líquido do exercício. O estoque deve desenvolver suas atividades como um componente regulador, em que os materiais chegam à empresa de maneira rápida, em que tem uma necessidade de produtos que um momento eleva ou reduz, segundo suas variações (RODRIGUES, 2015).

\subsection{PARECER DE AUDITORA EXTERNA JUNTO AOS ESTOQUES}

Crepaldi (2017), afirmam que os pareces de auditoria externa, começam com as demonstrações contábeis que se concentram em um conjunto de técnicas e procedimentos que possuem o objetivo, o fornecimento de um documento acerca da conformidade ou não conformidade, envolvido aos princípios essenciais de contabilidade e suas leis.

Todo parecer de auditoria segue primeiro a linha de investigação, conduzindo os preceitos determinados pela contabilidade, logo, cada parecer, é independente com informações indispensáveis para a empresa, caso surjam problemas, resolver 
conforme suas técnicas. Esse controle é recomendado para todas as organizações, que visam crescimento, sobre sua imagem e finanças, esses fatores, devem buscar a verdade dos quantitativos, qualitativos e as mudanças sofridas no tempo avaliado (CUNHA, 2019).

\subsection{RELATÓRIOS CONTÁBEIS}

Segundo Farias (2020), as informações contábeis passam por análises de seus administradores com a objetivo de controlar as operações, avaliando com parceiros de negócios, isto é, fornecedores e clientes, passando ainda por uma análise da imagem da empresa perante investidores e credores. Os pareceres contábeis são definidos como documentos que apontam de forma clara as informações técnicas, e de modo geral os dados colhidos pelos setores de contabilidade das empresas, incluindo os valores de despesas, impostos e custos, dentre outros (JIAMBALVO, 2013).

Comumente, os relatórios são realizados mensal, anual ou trimestralmente, seguindo essa sequência, é possível estipular as políticas exigidas pela empresa. Os processos contábeis são importantes, principalmente para controlar os gastos acessivos, são indispensáveis para a tomada de decisão que ocorrem na empresa, e todo valor do relatório, serve como suporte e apoio aos empresários (MONTOTO, 2014).

Para ludícibus (2017), os dados e relatórios contábeis têm por objetivo informar como está o balanço da empresa e sua posição financeira. É importante compreender que todo trabalho que envolve a busca de propostas sobre setores de uma empresa pede competência, por esses documentos terem uma função relevante para o gerenciamento e os negócios. 


\section{MATERIAIS E MÉTODOS}

Nesta seção, apresenta-se o delineamento metodológico do estudo. Apresentando o trabalho quanto ao método da pesquisa, natureza da pesquisa, do ponto de vista aos objetivos da pesquisa e enquanto aos instrumentos. Esta pesquisa é composta de informações como foram coletadas, quais os processos metodológicos que que baseiam todo procedimento da pesquisa científica, é o método existente a disposição do pesquisador para penetrar sobre o método de estudo.

\subsection{PROCEDIMENTOS METODOLÓGICOS}

Trata-se de uma pesquisa bibliográfica, de caráter exploratório, descritivo e qualitativo baseado em artigos científicos, utilizando como fontes de dados secundários, com pesquisas de vários autores que se voltam para a temática "Auditoria Externa", extraídas de páginas da internet, livros, e artigos que se encontravam nas bases de dados: SciELO, LILACS e Google Acadêmico.

A revisão bibliográfica é parte de um material já elaborado de artigos, livros, teses e monografias, na verdade, boa parte dos estudos é desenvolvida pautada em outras publicações sobre o assunto, seja como fonte de consulta ou como ponto de partida (MARCONI; LAKATOS, 2017).

É uma pesquisa realizada a partir de pesquisas em livros, monografias, e artigos que se encontram nas bases de dados, SCIELO, LILACS, Google Acadêmico e em sites da internet sobre a temática Auditoria Externa no Estoque. O estudo de revisão integrativa da literatura, é formado por seis etapas: verificação do problema, determinação de critérios de inclusãol exclusão (escolha da amostra), determinação das informações a serem retiradas dos artigos selecionados, investigação das informações, análises dos resultados e demonstração da revisão.

RC: 100655

Disponível em: https://www.nucleodoconhecimento.com.br/contabilidade/processosde-controle 


\subsubsection{QUANTO A NATUREZA}

Esse estudo trata-se de uma pesquisa básica e de abordagem qualitativa, realizada a partir de levantamento qualitativo. A pesquisa básica, visa gerar novas aprendizagens, necessárias para o desenvolvimento da Ciência, sem aplicação prática determinada. Compreende interesses universais e verdades (VERGARA, 2013).

De acordo com Gil (2017), a pesquisa básica pretende buscar o desenvolvimento do conhecimento científico, sem nenhuma preocupação com a aplicação rápida dos resultados a serem obtidos. O presente estudo baseia-se nas pesquisas em trabalhos que se direcionam para as respostas de perguntas que possam elevar o conhecimento que se tem sobre o mudo e tudo que o envolve. Ela é incentivada pela curiosidade e descoberta em determinado assunto, o que possibilitará melhor aquisição de conhecimento e debate.

Esta pesquisa destaca-se como uma abordagem qualitativa, pois busca associar métodos qualitativos, já que possibilita um suporte conceitual mais abrangente para análise e validação das conclusões dos estudos. Marconi e Lakatos (2017) afirma que a abordagem qualitativa se refere a um estudo tem como finalidade analisar e identificar aspectos de forma aprofundada, identificando a heterogeneidade do corpo humano, e disponibilizando estudos mais profundos das atitudes e investigações.

Constitui-se como uma abordagem qualitativa, pois se direcionará para aspectos que se voltam para a realidade, mas, que não são quantificados, direcionando-se apenas para o entendimento das dinâmicas das relações sociais.

\subsubsection{QUANTO AOS FINS}

Quanto aos objetivos, classifica-se de forma descritiva, conforme afirma Markoni e Lakatos (2017), no estudo descritivo o pesquisador se limita a "apresentar o evento apreciado, sem influenciar relações de causalidade entre os aspectos pesquisados". 
O autor inteira que esta categoria se contrapõe à pesquisa experimental em que investigador produz juízo de valor no que envolve ao assunto examinado.

As pesquisas descritivas retratam as características de um fenômeno ou pessoas. Podem ser também identificadas as conexões entre as variáveis. Classificam-se uma diversidade de números e grande parte são desenvolvidas com propósitos profissionais possivelmente adequa-se nessa categoria (GIL, 2017).

O interessante que a pesquisa descritiva é que ocorre uma formação de pesquisas científicas, visando fornecer o percurso certo para o alcance dos objetivos e para caracterizar uma população. A pesquisa se destaca com etapa em qual faz parte da metodologia científica, que condiz à observação, coleta, análise e interpretação de fatos e fenômenos que acontece dentro de seus nichos, situações e ambientes naturais da existência.

\subsubsection{QUANTO AOS MEIOS}

Filho e Filho (2015) descrevem que a pesquisa bibliográfica é capacidade essencial nos cursos de graduação, dado que, envolve a primeira etapa para todos os trabalhos acadêmicos. Uma pesquisa de campo ou laboratório envolve, precisamente, a pesquisa bibliográfica introdutória. Painéis, debates, seminários, monográficas, resumos críticos, não destituem a pesquisa bibliográfica.

Segundo Gil (2017) a pesquisa bibliográfica tem como vantagem a possibilidade de possibilitar que o pesquisador 0 alcance de uma diversidade de fenômenos abrangente, do que poderia atingir diretamente.

A pesquisa bibliográfica normalmente é a primeira etapa de toda pesquisa científica, visa elucidar um problema começando das referências exteriorizadas. Foram utilizados os seguintes critérios de inclusão: artigo na íntegra, dissertação, monografias, online, disponíveis gratuitamente, nas línguas portuguesa e inglesa, e com um recorte de tempo de 11 anos (2010- 2021) conforme os descritores: "Empresas de Médio Porte", "Auditoria Externa", "Controle de Estoque" e "Inventário

RC: 100655

Disponível em: https://www.nucleodoconhecimento.com.br/contabilidade/processosde-controle 
de Estoque". E como os critérios de exclusão: materiais incompletos, não científicos e que não estavam nos descritores.

\section{CONSIDERAÇÕES FINAIS}

Observou-se no decorrer da pesquisa que as empresas têm se preocupando constantemente com melhorias em seus processos. Compreende-se que os resultados financeiros das organizações podem ocorrer pela falta de controle interno, assim, diversas empresas estão buscando auxílio de auditoria, por se apresentar como método adequado para identificação de falhas e para tomada de decisão.

Em resposta da questão da pesquisa: Como a auditoria externa pode contribuir nos processos de controle de estoques empresas de médio porte do ramo industrial? A auditoria externa contribui na melhoria dos processos de controle de estoque por meio de procedimentos como: inventario, planejamento, controle de etiquetas, corte de operações, movimentação interna e externo de produtos, identificação dos produtos, conforme exposto no desenvolvimento do presente artigo.

A auditoria tem importante atribuição de apresentar a empresa, onde estão ocorrendo falhas nos procedimentos e como está deve operar para as necessárias correções dentro dos processos. Os erros podem ser evitados, com controle nas parcelas das notas de entrada e saída, assim como, no controle de condicionais e devoluções.

A auditoria deixou de ser percebida somente uma ação fiscalizadora, e sim, como uma comprovação de integridade contábil da indústria, que busca realizar boas práticas contábeis através da demonstração de parecer com as comprovações e registros que evidenciam a veracidade dos fatos. Para fazer parte de uma nova cultura de gestão que contribui com o processo de tomada de decisão.

Deste modo, os resultados do objetivo geral foram alcançados, pois, a auditoria externa contribui com o controle de estoque, apurando dados operacionais e 
financeiros, visando alcançar a fidelidade dos dados, contribuindo com a tomada de decisão da gestão, regulando as atividades diante o controle fiscalizatório. Ela identifica as informações operacionais e financeiras, com a finalidade de observar autenticidade dos dados, contribuindo com a tomada de decisão nas empresas, regulando seu exercício diante o poder de fiscalização.

Os resultados dos objetivos específicos também foram alcançados, pode-se constatar que a auditoria é definida como o estudo de todas as tarefas realizadas pela empresa, visando identificar as ações das organizações se está conforme o planejado, ou de acordo com as normas estabelecidas conforme legislação.

Sobre os procedimentos de auditoria externa percebeu-se que ela tem como finalidade elevar o grau de confiança das demonstrações contábeis, tem atribuição de realizar inspeções de documentos que contenham informações do que ocorre no estoque, refletindo sobre os problemas identificados. Porém, para que seja realizada a auditoria é importante compreender o estoque, para que as indústrias atendam às necessidades e reposição do mercado.

Diante disso, é importante que ocorram novas pesquisas com a finalidade de alcançar melhores esclarecimentos sobre a realização da auditoria, que tem um papel fundamental para a melhoria dos processos e controle nos estoques.

\section{REFERÊNCIAS}

ALMEIDA, Marcelo Cavalcanti. Auditoria: Um curso moderno e completo. São Paulo: Atlas, 2012.

AMORIM, F.C.; et al. Implantação do Controle de Estoque de Matéria-Prima no Almoxarifado de uma Fábrica de Móveis Planejados. Monografia (Engenharia de Produção)- Universidade Federal de Ouro Preto. João Monlevade, 2016.

AVILA, P. R. Análise do mercado de produtos orgânicos com ênfase na pecuária orgânica de 2012 a 2019. Caxias do Sul, 2020.

RC: 100655

Disponível em: https://www.nucleodoconhecimento.com.br/contabilidade/processosde-controle 
BARBOSA, A. Proposta de elaboração de um controle de estoque em microempresas (bares) no município de Caçador-SC. 2017.

BETENCOURT, C. PEPS, UEPS e Custo médio - O que é e como funciona. 2018.

CARVALHO, B. B. Contabilidade gerencial como ferramenta para gestão de microempresas e empresas de pequeno porte. Lages, 2019.

CARVALHO, L. F.; PEREIRA, N.A importância da auditoria externa na detecção de fraudes. 2016.

COELHO, J. M. Estoques- Métodos de Valoração. 2017.

CONSELHO REGIONAL DE CONTABILIDADE DO CEARÁ - CRC-CE. Auditoria Contábil. 2016.

CREPALDI, Silvio Aparecido; CREPALDI, Guilherme Simões. Auditoria contábil: teoria e prática. 10. ed. - São Paulo: Atlas, 2016.

CREPALDI, Silvio Aparecido; CREPALDI, Guilherme Simões. Contabilidade gerencial: teoria e prática. São Paulo: Atlas, 2017.

CUNHA, J. K. M. A importância da auditoria externa no processo de tomadas de decisão das organizações. Fortaleza, 2019.

DA SILVA, R.V.C.; OLIVEIRA, T.A. A Utilização da Curva ABC na Gestão de Estoques. Estudo de caso em uma indústria alimentícia na cidade de Mamanguape - $\quad 2019 . \quad$ PB, Disponível em: https://www.iesp.edu.br/sistema/uploads/arquivos/publicacoes/a-utilizacao-da-curvaabc-na-gestao-de-estoques-estudo-de-caso-em-uma-industria-alimenticia-na-cidadede-mamanguape-pb-autor-silva-ranie-vinicius-costa-da-.pdf. Acesso em: 24 agos.2021. 
DANTAS, K. P. Gestão de estoque: um estudo de caso no setor de produtos acabados da indústria de tempero Regina Ltda. Revista Colóquio: Administração e Ciência, Mossoró-RN, v. 02, 2020.

FARIAS, C. J.; ANJO, A. K. Análise comparativa dos principais métodos de avaliação de estoques. 2018.

FARIAS, T. T. B. As informações contábeis gerenciais em micro e pequenas empresas: um estudo nas pizzarias da cidade de João Pessoa - PB. João Pessoa, 2020.

FILHO, João Lúcio da Silva. Auditoria dos Estoques. 34f. Monografia (Especialização em Auditoria Fiscal-Contábil) - Universidade Federal da Paraíba, João Pessoa, 2008

FILHO, M. C. F.; FILHO, E. J. M. A. Planejamento da pesquisa científica. 2. ed. São Paulo: Atlas, 2015.

GIL, A. C. Como elaborar projetos de pesquisa. 6. ed. São Paulo: Atlas, 2017.

GONÇALVES, L. C. Gestão e controle de estoques. Notas de Aula. Faculdade de Tecnologia da Zona Sul/FATEC, São Paulo, 2017. Disponível em: file:///C:/Users/Dora/Downloads/Dialnet-

AvaliacaoDosPrincipaisFatoresQuelmpactamAGestaoECo-6786931.pdf. Acesso em: 06 mar 2021.

IUDÍCIBUS, Sérgio de. Análise de Balanços. 11. ed. São Paulo: Atlas, 2017.

JIAMBALVO, James. Contabilidade Gerencial. 3. ed. Rio de Janeiro: LTC, 2013.

LINS, Luiz dos Santos. Auditoria: uma abordagem prática com ênfase na auditoria externa. 4. ed. São Paulo: Atlas, 2017. 
MACEDO, G. D. Os desafios de utilizar o método do fluxo de caixa descontado na avaliação de companhias de capital aberto em economias emergentes. São Leopoldo, 2017.

MACHADO, C. M.; et al. Healthcare lean operations: Building an effective management framework. Organization, v. 1, n. 4, 2015.

MACHADO, N. F. Impacto da Covid-19 evidenciando das demonstrações financeiras das maiores companhias varejistas brasileiras. 2020.

MARCONI, Marina de Andrade; LAKATOS, Eva Maria. Metodologia do Trabalho Científico. 8. ed. São Paulo: Atlas, 2017. 256 p.

MARTINS, Carlos Alberto; CONCEIÇÃO, Jhonnys Felipe. Gestão de estoques: análise no estoque de uma microempresa de aquecedores. Florianópolis, 2019.

MARTINS, R. B. Ferramentas de contabilidade gerencial adotadas por micro e pequenas empresas. 2018. Trabalho de Conclusão de Curso - Universidade Federal da Paraíba, João Pessoa, 2018.

MENDONÇA, M. F. Controle de estoque em lojas de móveis: um estudo no distrito de Guassussê, Orós-CE. Revista Livre de Sustentabilidade e Empreendedorismo, v. 4, n. 5, p. 66-91, set-out 2019. Disponível em: file://C:/Users/Dora/Downloads/274-992-1-PB.pdf Acesso em: 06 mar 2021.

MONTOTO, Eugênio. Contabilidade geral e análise de balanços esquematizado. 3. ed. São Paulo: Saraiva, 2014.

MOREIRA, Aleziandra; BARAN, Kelly. A importância da auditoria interna para as organizações. Revista Científica Multidisciplinar Núcleo do Conhecimento, v. 05, n. 02, 2018.

NASCIMENTO, S. S. Auditoria interna e sua dinâmica no contexto organizacional. Campo Grande 2020. 
NUNES, S. F.; et al. O Dimensionamento dos níveis de estoque na indústria de transformação: um estudo em uma fábrica de isotérmicas. 2020.

PORTAL EDUCAÇÃO. Fundamentação Teórica. 2021. Disponível em: https://siteantigo.portaleducacao.com.br/conteudo/artigos/educacao/fundamentacaoteorica/31156. Acesso em: 31 agos.2021.

PYKE, D.; SILVER, E.; THOMAS, D. Inventory and Production Management in Supply Chains. New York, USA: CRC Press. p. 533, 2017.

RODRIGUES, A. L.; et al. A Importância da Gestão de Estoque na obtenção de Êxito na Administração Organizacional. Id on Line Rev. Mult. Psic., v. 14, n. 49 p. 518530, fevereiro/2020.

RODRIGUES, B. M. Gestão de estoque: controle de reposição de itens de demanda independente, em uma indústria de equipamentos laboratoriais. UNIVERSIDADE SÃO FRANCISCO, 2015.

RUSSO, Clovis Pires. Armazenagem, Controle e Distribuição/ Clovis Pires Russo. - Curitiba: InterSaberes, 2013. Disponível em: http://idaam.siteworks.com.br/jspui/bitstream/prefix/190/1/QUAL\%20\%c3\%89\%20A\% 20IMPORT\%c3\%82NCIA\%20DO\%20CONTROLE\%20DE\%20ESTOQUE\%20NAS\% 20IND\%c3\%9aSTRIAS\%20NO\%20POLO\%20INDUSTRIAL\%20DE\%20MANAUS.pd f. Acesso em: 24 ago.2021.

SANTOS, O.G.S.; BORGES, A.A. A Importância do Controle do Estoque: Um Estudo de Caso no Ramo Farmacêutico em Itumbiara-GO. 2016. Disponível em: https://unifasc.edu.br/wp-content/uploads/2020/07/11-A-IMPORT\%C3\%82NCIA-DOCONTROLE-DE-ESTOQUE.pdf>. Acesso em: 22 agos.2021.

SEBRAE. Participação das Micro e Pequenas Empresas na Economia Brasileira. Brasília, 2014. 
SILVA, D. A. Redução dos Custos de Qualidade em uma Empresa do PIM. Manaus, 2018.

SILVA, K. M. A importância do sistema Kanban para o gerenciamento e controle de estoque de uma empresa. 2019.

SILVA, M. L. V.; LOOS, M, J. A importância da utilização de indicadores de desempenho de gestão de estoques na logística de suprimentos de uma indústria calçadista. Revista FFBusiness, Fortaleza - V.14, - № 17 - jan. 2016.

SILVA, V. G. M.; et al. Controle de estoque: um estudo sobre a eficiência da gestão de estoque numa distribuidora atacadista em Divinópolis, MG. Research, Society and Development, Divinópolis-MG, v. 7, n. 5, p. 01-16, 2018.

SOUZA, Elana Silva de. Características e Impactos da Indústria 4.0: Percepção de Estudantes de Ciências Contábeis. 2018.

TRINDADE; PEREIRA; THEREZA, M. A. A importância da auditoria interna nas empresas. Organizações e Sociedade, turama (MG), v. 6, n. 5, p. 98-107, jan./jun. 2, 2017. Disponível em: file:///C:/Users/Dora/Downloads/274-749-1-SM.pdf. Acesso em: 22 ago. 2021.

VARIAN, H. R. Microeconomia: uma abordagem moderna. 9. ed. - Rio de Janeiro: Elsevier, 2015.

VERGARA, Sylvia. Projetos e Relatórios de Pesquisa em Administração. $14^{\circ}$ ed. - São Paulo: Atlas, 2013.

Enviado: Outubro, 2021.

Aprovado: Novembro, 2021. 